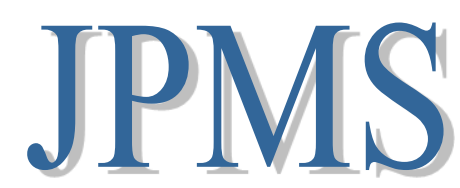

Jurnal Pengabmas Masyarakat Sehat

ARTIKEL HASIL PENGABDIAN KEPADA MASYARAKAT

URL artikel: http://ejournal.poltekkes-denpasar.ac.id/index.php/JPMS/article/view/jpms2405

\title{
Gambaran Pengetahuan Tentang Rumah Tunggu Kelahiran Di Tamher Timur
}

\author{
Oktovina Sofiah Rattu ${ }^{1 k}$; Alfa Fitria ${ }^{1}$ \\ ${ }^{1}$ Sekolah Tinggi Ilmu Kesehatan Maluku Husada, DIII Kebidanan \\ Email penulis korespondensi $\left({ }^{\mathrm{K}}\right)$ : Oktovina@gmail.com
}

\begin{abstract}
The birth waiting home program is listed in the Regulation of the Minister of Health of the Republic of Indonesia Number 82 of 2015 concerning technical instructions for the use of special allocation funds in the health sector and supporting facilities and infrastructure for the health sarpras sub-sector for the 2016 fiscal year in article 5 concerning the operational costs of the birth waiting house. In Indonesia, especially in the archipelago, the mortality rate for pregnant women is still high, thus indicating a low degree of health. This is caused by various factors including geographic, socio-economic factors, limited means of transportation, limited health facilities and health workers. To overcome this, we need a special place close to basic health care facilities or a hospital that can be temporarily occupied by pregnant women before labor arrives called the Home Waiting for Birth (RTK), which has an important function as a temporary residence for pregnant women until they arrive during childbirth.
\end{abstract}

Keywords: Knowledge, Home Waiting For Birth

\section{Pendahuluan}

Program rumah tunggu kelahiran tercantum dalam Peraturan Menteri Kesehatan Republik Indonesia Nomor 82 Tahun 2015 tentang petunjuk teknis penggunaan dana alokasi khusus bidang kesehatan serta sarana dan prasarana penunjang subbidang sarpras kesehatan tahun anggaran 2016 pada pasal 5 tentang biaya operasional rumah tunggu kelahiran. ${ }^{(1)}$ Setiap dua menit, di suatu tempat di dunia, seorang perempuan meninggal akibat komplikasi kehamilan dan hampir 10.000 wanita meninggal setiap tahun karena masalah dalam kehamilan dan persalinan. ${ }^{(2)}$

Di Indonesia khususnya wilayah kepulauan angka kematian ibu hamil masih tinggi sehingga menunjukkan derajat kesehatan yang rendah. Hal ini diakibatkan oleh berbagai faktor diantaranya faktor geografis, sosial ekonomi masyarakat, keterbatasan alat transportasi, keterbatasan fasilitas kesehatan dan tenaga kesehatan. Mengatasi hal tersebut, diperlukan suatu tempat khusus yang dekat dengan fasilitas pelayanan kesehatan dasar atau rumah sakit yang dapat dihuni sementara oleh ibu hamil sebelum persalinan tiba yang disebut Rumah Tunggu Kelahiran (RTK), yang memiliki fungsi penting sebagai tempat tinggal sementara bagi ibu hamil sampai tiba saat persalinan. ${ }^{(3)}$ 
Keberhasilan upaya kesehatan ibu di antaranya dapat di lihat dari indikator Angka Kematian Ibu (AKI). AKI adalah jumlah kematian ibu selama masa kehamilan, persalinan dan nifas yang disebabkan oleh kehamilan, persalinan, dan nifas atau pengelolaannya tetapi bukan karena sebabsebab lain seperti kecelakaan, terjatuh, dan lainnya. ${ }^{(4)}$ Upaya percepatan penurunan AKI dapat dilakukan dengan menjamin agar setiap ibu mampu mengakses pelayanan kesehatan ibu yang berkualitas, seperti pelayanan kesehatan ibu hamil, pertolongan persalinan oleh tenaga kesehatan terlatih di fasilitas pelayanan kesehatan, perawatan pasca persalinan bagi ibu dan bayi, perawatan khusus dan rujukan jika terjadi komplikasi, kemudahan mendapatkan cuti hamil dan melahirkan, dan pelayanan keluarga berencana.

\section{Metode Pengabdian}

Kegiatan pengabdian kepada masyarakat dilaksanakan di Tamher Timur, pada tanggal 09-14 Maret 2020. Sasaran dari kegiatan pengabdian masyarakat ini adalah ibu hamil trimester III yang berada di lokasi penelitian. Kegiatan pengabdian ini berupa pemberian penyuluhan mengenai pengetahuan tentang rumah tunggu kelahiran menggunakan media leaflet, laptop, LCD, kuesioner dan speaker. Kegiatan pengumpulan data akan dilakukan dengan pre-test dan post-test. Teknik pengumpulan data yang digunakan adalah teknik sampling aksidental yaitu siapa saja yang secara kebetulan bertemu dengan peneliti dapat digunakan sebagai sampel penelitian sesuai dengan kriteria inklusi dan eksklusi. Dalam kegiatan pengabdian masyarakat ini pengolahan dan analisis data menggunakan analisis univariat, hasil kuesioner yang didapatkan akan di tabulasi kemudian di analisis secara manual dan dibuatkan pembahasan.

\section{Hasil dan Pembahasan}

\section{A. Hasil}

\section{Hasil Pre-test dan Post-test Pengetahuan Tentang Rumah Tunggu Kelahiran di Tamher Timur}

Dari hasil data penelitian menunjukan bahwa adanya peningkatan pengetahuan ibu tentang rumah tunggu kelahiran sebesar $76,1 \%$. Pengetahuan ibu mengenai rumah tunggu kelahiran yang benar saat pre-test sebesar 33,3\%, setelah dilakukan penyuluhan mengenai rumah tunggu kelahiran, sampel mendapatkan pemahaman dan pengetahuan sehingga nilai post-test meningkat sebesar $76,1 \%$. Data selengkapnya dapat dilihat pada tabel 1 .

Tabel 1. Hasil Pre-test dan Post-test Pengetahuan Ibu Tentang Rumah Tunggu Kelahiran di Tamher Timur

\begin{tabular}{ccccccc}
\hline \multirow{2}{*}{ No } & \multicolumn{3}{c}{ Pre-test } & \multicolumn{3}{c}{ Post-test } \\
\cline { 2 - 7 } & Pengetahuan & $\mathrm{f}$ & $\%$ & Pengetahuan & $\mathrm{f}$ & $\%$ \\
\hline 1 & Baik & 7 & 33,3 & Baik & 16 & 76,1 \\
2 & Kurang & 14 & 66,7 & Kurang & 5 & 23,8 \\
\hline & Jumlah & 21 & 100,0 & Jumlah & 21 & 100,0 \\
\hline
\end{tabular}




\section{B. Pembahasan}

Menurut asumsi peneliti pengetahuan seseorang akan sangat memengaruhi terjadinya atau terciptanya perilaku. Pengetahuan mengenai pentingnya Rumah Tunggu Kelahiran (RTK) akan membuat seorang ibu hamil yang nantinya akan melahirkan terlebih dahulu memanfaatkan RTK yang ada. Rumah tunggu kelahiran teridentifikasi memiliki alur teknis, target utama dari rumah tunggu kelahiran (RTK) adalah Ibu hamil risiko tinggi, rumah tunggu kelahiran teridentifikasi mempermudah akses bagi ibu hamil risiko tinggi yang bertujuan menurunkan angka kematian ibu , strategi lingkungan kondusif dan penciptaan alur komunikasi bagi ibu/target rumah tunggu kelahiran maupun tenaga kesehatan bertujuan untuk menurunkan angka kematian ibu dan mempermudah akses fasilitas pelayanan kesehatan bagi ibu hamil

Dukungan informasi tentang rumah tunggu kelahiran yang diberikan oleh keluarga supaya ibu bersalin dan keluarga lainnya memahami tentang manfaat rumah tunggu kelahiran.dukungan informasi yang positif akan memengarui ibu bersalin untuk memutuskan tinggal di rumah tunggu kelahiran. Selain itu suport keluarga kepada ibu bersalin dan memberikan kepercayaan kepada ibu bersalin bahwa rumah tunggu kelahiran sangat dibutuhkan oleh ibu bersalin terutama pada ibu bersalin dengan risiko tinggi. Hal ini dikarenakan informasi mengenai program rumah tunggu kelahiran hanya di dapat kalau ibu hamil didampingi oleh keluarga untuk datang memeriksakan kehamilannya ke tenaga kesehatan sehingga ibu hamil mendapat informasi tentang rumah tunggu kelahiran dari tenaga kesehatan

\section{Simpulan dan Saran}

Pembentukan dan penerapan kebijakan rumah tunggu bersalin berbasis gugus pulau merupakan salah satu bentuk inovasi dalam upaya memperpendek rentang kendali dan keterjangkauan pelayanan kesehatan bagi ibu hamil. Rumah tunggu kelahiran merupakan bangunan di dekat fasilitas kesehatan sebagai tempat tinggal sementara ibu hamil dan pendampingnya guna mendekatkan akses ke fasilitas pelayanan kesehatan. Diharapkan dengan kegiatan ini tenaga kesehatan melakukan promosi kesehatan mengenai rumah tunggu kelahiran dalam upaya mencegah terjadinya keterlambatan penanganan terutama di daerah sulit akses dan berperan dalam upaya percepatan penurunan Angka Kematian Ibu.

\section{Daftar Pustaka}

1. Menteri Kesehatan Republik Indonesia, Peraturan Menteri Kesehatan Republik Indonesia Nomor 82,2015

2. UNICEF. Risiko Kematian Ibu dan Anak Indonesia masih Tinggi Walaupun Angka Kematian SudahMenurun.2015.Tersediapada:https://www.unicef.org/health/files/Innovative_Approaches_ MNH_CaseStudies-2013.pdf

3. WHO. Maternity Waiting Homes: A review of experiences, 2016.96(21),1-44. Tersedia di : http://medcontent.metapress.com/index/A65RM03P4874243N.pdf\%5Cnhttp://scholar.google.co $\mathrm{m} / \mathrm{scholar}$ ?hl=en\&btnG=Search\&q=intitle:Maternity+Waitin+Homes:+A+review+of+experience

4. Manuaba IBG. Ilmu kebidanan, penyakit kandungan \& keluarga berencana untuk pendidikan bidan. In EGC; 1998. 